\title{
Depression and Osteoporosis in Men: Association or Casual Link?
}

\author{
Ioannis Ilias, ${ }^{1}$ Salvatore Alesci, ${ }^{2}$ Philip W. Gold, ${ }^{2}$ George P. Chrousos ${ }^{3}$ \\ ${ }^{1}$ Department of Pharmacology, Medical School, University of Patras, Rion-Patras GR-26504, Greece, ${ }^{2}$ Clinical \\ Neuroendocrinology Branch, National Institute of Mental Health, National Institutes of Health, Bethesda, MD \\ 20892-1583, USA, ${ }^{3} 1^{\text {st }}$ Department of Pediatrics, University of Athens, Medical School, Agia Sophia Hospital, \\ Athens GR-11527, Greece
}

\begin{abstract}
The longer life expectancy of women than that of men and, therefore, the longer exposure to fracture risk has, at least partially, led to neglect of osteoporosis in men. Recently, unipolar depression, which is $\mathbf{2}$ times more frequent in women than in men, has been linked to osteoporosis. However, it is quite possible that this diagnosis may escape detection in men because of a different behavioral phenotype between the genders. A potential mechanism of bone loss in depression has been proposed, involving concurrent activation of the hypothalamopituitary-adrenal and sympatho-adrenal axes, suppression of the gonadal and somatotrophic axes, and high inteleukin-6 and low leptin levels. We suggest that similar neurohormonal changes may cause osteoporosis in men.
\end{abstract}

Key words: Depression, Male, Osteoporosis

\section{OSTEOPOROSIS IN MEN}

Over the last two decades, osteoporosis has received increasing attention as a major health problem worldwide. It has been estimated that in the United States alone, 10 million people suffer from osteoporosis, and 18 million more are afflicted with osteopenia, which has been associated with an increased risk for nontraumatic fractures later in life. ${ }^{1}$ Osteoporosis is still regarded mainly as a women's disease. This could be attributed to a higher bone mass in men and the absence of menopause, as well as to the fact that men undergo fewer bone mineral

Address correspondence and requests for reprints to: Ioannis Ilias, Department of Pharmacology, Medical School, University of Patras, Rion-Patras 26504, Greece, Phone: + 30 2610-997638, Fax: + 302610 994720, e-mail: iliasi@upatras.gr Received 10-10-05, Revised 25-11-05, Accepted 00-00-05 density (BMD) measurements than women. ${ }^{2}$ Since life expectancy has considerably increased worldwide over the last century (with men's longevity, however, still lagging somewhat behind that of women: $75 \mathrm{v} .80$ years in the U.S.), more and more older men are now are now expected to develop multiple coexisting illnesses contributing to bone loss. With advancing age, the likelihood of accidental falls also increases and this is accompanied by an elevated likelihood of sustaining fractures. In the following review we examine the tentative association of depression and osteoporosis in men.

\section{Epidemiology of low bone mineral density in men}

Investigators have used data from the Third National Health and Nutrition Survey (NHANES III) to estimate the prevalence of low BMD in the United States. ${ }^{3}$ Specifically, they applied the World 
Health Organization (WHO) criteria to define osteopenia $(-2.5 \mathrm{SD} \leq \mathrm{BMD}$ t-score $\leq-1 \mathrm{SD})$ and osteoporosis (BMD t-score $<-2.5 \mathrm{SD}$ ) and used two different cutoffs for men, based either on young normal male or female reference groups aged 2029 years. With male cutoffs, $28 \%$ to $47 \%$ (9 to 13 million) of men aged $50+$ years were estimated to have osteopenia and $3 \%$ to $6 \%$ of men (1 to 2 million) osteoporosis. Using female cutoffs, 15 to $33 \%$ ( 5 to 11 million) had osteopenia and 1 to $4 \%$ ( 0.3 to 1 million) had osteoporosis.

\section{Epidemiology of osteoporotic fractures in men}

It is a common assumption that women sustain more fractures than men. However, the relation between BMD and fractures is similar in men and women, ${ }^{4}$ and cumulative cross-sectional data on fracture incidence at all ages, all sites and all activities have shown that men are more likely to incur fractures than women. ${ }^{5}$ The most common osteoporotic fractures are those of the hip and vertebral bodies, followed by those of the forearm, humerus, tibia, iliac bones and the ribs. Of the 1.7 million hip fractures that occurred worldwide in 1990, $28 \%$ were in men and, according to a projection that takes into account the increasing longevity of men, out of 4 million hip fractures expected in 2025, 1.2 million will occur in men. ${ }^{6}$ The lifetime risk of hip fracture in men has been estimated at $6 \% .^{7}$ Hip fractures account for the greatest morbidity and mortality among fractures, which are higher in men than women for reasons that remain unclear. ${ }^{8} \mathrm{Up}$ to $50 \%$ of men need to be hospitalized after a hip fracture and up to $80 \%$ of those who survive are unable to regain their normal level of functional independence. ${ }^{9}$ Moreover, men have a two-fold greater likelihood of dying in hospital after a hip fracture compared to women. ${ }^{10}$ In men aged 60 to 69 years, the decrease in life expectancy after a hip fracture is 11.5 years. ${ }^{8}$ The incidence of vertebral fractures is probably underestimated, as not all patients may seek medical attention because of the nonspecificity of the symptoms associated with such fractures, such as low back-pain, height loss and kyphosis (usually revealed by radiological screening). ${ }^{11}$

\section{DEPRESSIVE DISORDERS}

Depressive disorders affect the person's body, mood and cognition and take different forms, including major (or unipolar) depression, dysthymia and bipolar disorder, as described in the fourth edition of the American Psychiatric Association's Diagnostic and Statistical Manual of Mental Disorders (DSM-IV-TR). ${ }^{12}$ Major depression must be differentiated from dysthymia, a less severe type of depression involving long-term chronic symptoms that may interfere with the person's social functioning and feeling of well-being, but are not disabling. Bipolar disorder (or manic-depressive disorder) is characterized by cycling mood-swings between euphoria and dysphoria.

\section{Unipolar Depression in men}

The WHO estimates that depression is currently the fourth leading cause of worldwide, and predicts that by the year 2020 it will be the second. ${ }^{13}$ As with osteoporosis, women have mostly been the main focus of attention for depression, because the prevalence of this disorder appears to be higher in women than in men. Epidemiological studies have consistently reported that major depression is twice as prevalent in women as in men. ${ }^{14}$ Thus, according to the National Comorbidity Survey I, the lifetime prevalence of major depression in men in the United States is $12.7 \%$ compared to $21.3 \%$ in women, while the female-to-male relative risk is $1.7 .{ }^{15}$

Several hypotheses have been put forward to explain the gender difference in the prevalence of unipolar depression. Biological theories have focused on sex-differences in neurotransmitters and neuroendocrine systems ${ }^{16,17}$ as well as on genetic factors. ${ }^{18}$ On the other hand, psychosocial theories have pointed to social childhood environment, social roles and cultural norms, economic dependence, vulnerability and coping style. ${ }^{19}$ Finally, diagnostic biases, including the tendency of females to more often report depressive symptoms than males together with gender differences in help-seeking behavior and measurement procedures cannot be excluded. ${ }^{20}$ Another important gender-related difference is that suicide attempts are more common in women, while men more often completed suicides. ${ }^{21}$ 
It has recently been suggested that the presentation of depressive symptoms may be different in males and females. The Gotland Study has shown that, in addition to the classic symptoms cited by the DSM IV, the male depressive syndrome may include several atypical manifestations, which may lead family/general practitioners and even psychiatrists to mistake depression for diagnoses of comorbid states, such as alcoholism, drug abuse or antisocial personality disorder. ${ }^{22}$ Further support for this concept comes from the finding that in religious communities that do not permit antisocial behavior or alco$\mathrm{hol} / \mathrm{drug}$ use, unipolar depression is equally distributed among men and women. ${ }^{23,24}$ To better identify depressed males, the Gotland Male Depression Scale includes, in addition to the typical features of unipolar depression, several atypical manifestations. Educational programs and improvements of psychiatric services on the island of Gotland have been accompanied by a significant decrease in the rate of male suicides. ${ }^{25}$

\section{DEPRESSION AND OSTEOPOROSIS IN MEN: ASSOCIATION OR CASUAL LINK?}

Several studies have examined the association between major depression and low BMD. Most of the studies on depression and osteoporosis have been conducted on postmenopausal women and only a few of them have included depressed premenopausal women or men. Recently, a cross-sectional study evaluated the association between BMD (measured by DEXA) and depression in a population of 1,566 subjects aged 65 or older, randomly selected from the participants of the Cardiovascular Health Study, a longitudinal, long-term follow-up study conducted at the University of Pittsburg and the University of California at Davis Clinical Centers. Of the $16 \%$ subjects clinically diagnosed with major depression by means of the Center for Epidemiological Studies 10-item Depression Scale (CES-Dm), 9\% had low BMD. Patients with higher CES-Dm scores also registered lower BMD, after adjustments for bone mass index, age, kilocalories of activity, gender, race, smoking and drinking. ${ }^{26}$

\section{Review of the published studies on osteoporosis and depression in men}

In a population of 80 patients with depression (27 men, mean age: 58 years; 53 women, mean age: 62 years), diagnosed according to the DSM III R, the lumbar-spine BMD values measured by quantitative computed tomography (qCT) were approximately $15 \%$ lower than in a group of 88 nondepressed subjects (30 men, mean age: 63 years and 58 women, mean age: 58 years). ${ }^{27}$ Risk factors for bone loss, such as smoking, history of excessive or inadequate levels of exercise, or history of estrogen treatment did not yield any additional effect, suggesting an effect of depression per se on bone loss. A follow-up of this study, carried out on 18 depressed subjects (10 men, 8 women) and 21 age-matched nondepressed controls (14 men, 7 women) from the original cohort, showed that bone loss over 24 months was significantly greater in depressed subjects than in control subjects. Moreover, bone loss in depressed men was $6 \%$ greater than in depressed women. ${ }^{28}$

In a case series of psychiatric inpatients ( 35 men, mean age: 36 years and 33 women, mean age: 44 years) consecutively hospitalized for depression (diagnosed based on the DSM III R) or other mental conditions, depressed subjects $(n=21)$ had a significantly lower BMD (measured by dual-photon absorptiometry at the hip and spine) than age- and gender-matched controls. Again, bone loss was more severe in depressed men than in depressed women. A negative correlation between plasma cortisol and bone mineral density was observed in depressed subjects of both sexes, while in men there was a positive correlation between BMD and testosterone levels. ${ }^{29}$

In a recent large cross-sectional study of 2000 oriental men aged 65 to 92 years, $8.5 \%$ of the subjects were depressed and depression was associated with a 1.4-fold (95\% CI 1.00 to 2.08) relative risk of being diagnosed as having at least osteopenia (assessed by DEXA). ${ }^{30}$

\section{Limitations of the published studies on osteoporosis and depression in men}

The studies summarized here are important because they point to the tentative existence of an as- 
sociation between depression and osteoporosis in men. However, it is important to note some of their limitations. Most studies can establish only the existence of an association rather than a causal link between depression and osteoporosis. Different instruments have been used to diagnose and assess the severity of depression. The populations studied were heterogeneous: subjects who were actively depressed were often pooled together with subjects who only carried a history of depression. Retrospective evaluation of history of depression has limited reliability when it is solely based upon subject recollection. Furthermore, the sample size in some studies was small. Another issue that has not been explored is that depressed subjects may spend much time indoors, thus avoiding exposure to sunlight (leading to vitamin D deficiency) or lead sedentary lives. ${ }^{31}$

\section{Endocrine correlates of Depression in men: implications for bone loss}

Several endocrine changes have been described in depressed male patients. Some of them may negatively influence bone metabolism, ${ }^{32}$ as discussed below.

\section{Hypothalamo-pituitary-adrenal (HPA) and sympathoadrenal axes}

Neuroendocrine abnormalities are a common finding in depressed patients. The most consistent finding is that depressed subjects have levels of cortisol whose magnitude may sometimes resemble those seen in mild Cushing's disease.$^{33}$ In one study, the 24-h profile of plasma cortisol and corticotropin $(\mathrm{ACTH})$ was determined in 18 men suffering from major depressive illness (8 unipolar, mean age \pm SD: $50 \pm 10$ years; 10 bipolar, mean age \pm SD: $45 \pm 10$ years) and 7 control subjects; the patients were diagnosed with the Schedule for Affective Disorders and Schizophrenia instrument, the Research Diagnostic Criteria and the 24-item Hamilton Rating Scale. Patients were hospitalized for at least 15 days before the study and did not receive any medication during this interval. Blood sampling at 15minute intervals lasted 25 hours. Both unipolar and bipolar depressed patients had significantly higher 24-h mean cortisol levels than controls, while no significant difference in the 24-h mean ACTH level was found between depressed patients and controls. In addition, the nadir of cortisol secretion occurred almost 3 hours earlier in patients with unipolar depression, regardless of age, compared to young control subjects. ${ }^{34}$

A more recent study including 15 severely depressed (mean \pm SD Hamilton Depression Scale score: $30.4 \pm 6.7$ ) male inpatients (age 22-72 years) and 22 age-matched controls revealed significantly higher values of both mean 24-h cortisol and mean 24-h ACTH (24-h blood sampling with 30-minutes intervals) in depressed patients than controls, independently of age. The frequency of cortisol and ACTH pulses during the evening were also higher in depressed subjects. ${ }^{35}$ Increased cortisol levels have also been demonstrated in the urine and in the cerebrospinal fluid (CSF) of depressed men. ${ }^{36}$

Sympatho-adrenal dysregulation is another common finding in depressed subjects, as evidenced by increased catecholamine turnover and increased catecholamine urinary excretion in severe depression. ${ }^{37,38}$

The coexisting dysregulation of HPA and sympatho-adrenal axes in depression may result from a defect at or above the level of the hypothalamus, leading to hypersecretion of corticotropin-releasing hormone (CRH). Interestingly enough, ACTH response to exogenous ovine $\mathrm{CRH}$ is attenuated in depression, suggesting that the pituitary corticotroph cell is restrained by the negative feedback of glucocorticoids. ${ }^{33}$ Moreover, a statistically significant increase of CRH has been reported in the CSF of depressed patients. ${ }^{39}$ The positive correlation between CSF levels of CRH and CSF levels of norepinephrine and catecholamine metabolites in depression support the idea of a common central activation of HPA and sympathoadrenal axis by $\mathrm{CRH} .{ }^{40}$

Osteoporosis is a well-known consequence of both endogenous and exogenous glucocorticoid excess and hypercortisolism can be proposed as one of the mechanisms adversely affecting BMD in depressed patients. Bone loss occurs in 30 to $50 \%$ of patients under chronic treatment with corticosteroids and is more pronounced in trabecular than in cortical bone. Bone mass is only partially regained after remission of hypercortisolism, in a process that 
can take many years. ${ }^{41}$

\section{Gonadal axis}

Low levels of sex hormones have been frequently observed in depressed patients. Moreover, plasma testosterone levels were negatively correlated with the severity of depression, after correction for age, in 15 male depressed patients. ${ }^{42}$ More recently, the association between endogenous sex hormone levels and depression has been evaluated in a large cross-sectional study on a cohort of communitydwelling older men. Participants included 856 men (age: 50-89 yrs) who, between 1984 and 1987, had attended a diabetes study clinic and who were not using testosterone therapy. Depression was assessed using 18 of the 21 items on the Beck Depression Inventory (BDI). Only 25 men in this cohort had clinical depression (BDI score equal to or higher than 13 and/or current use of antidepressant). The BDI score was significantly inversely associated with bioavailable testosterone and dihydrotestosterone, independently of age, weight change and physical activity, as demonstrated by linear regression and quartile analysis. Bioavailable testosterone levels were $17 \%$ lower in the 25 men with clinically diagnosed depression than levels in all other men. Neither total testostorone/dihydrotestosterone nor total or bioavailable estradiol was associated with depressed mood. ${ }^{43}$ Another recent study reported significantly lower age-adjusted levels of daytime and nighttime testosterone and 24-hour mean testosterone in 15 male inpatients with moderate to severe major depression (diagnosed according to the DSM III-R criteria using a standardized interview) when compared to 22 healthy controls (age range: 22-85 years). ${ }^{44}$

Hypogonadism is the best-characterized primary medical cause of osteoporosis in men. Cross-sectional studies demonstrated that bone mineral density is reduced in primary ${ }^{45}$ and secondary hypogonadism. ${ }^{46}$ Men treated with finasteride, which converts testosterone to dihydrotestosterone, do not have accelerated bone loss. ${ }^{47}$

\section{Somatorophic axis}

Altered stimulated and spontaneous growth hormone $(\mathrm{GH})$ secretion has been reported in de- pressed patients. A decreased nocturnal GH release and $\mathrm{GH}$ response to a combined releasing hormone test was found in 6 depressed men off medications compared to 6 age-matched healthy men. ${ }^{48}$ In the same study, baseline GH levels (measured at 15minute intervals over 26 hours) were lower in depressed patients compared to controls.

Another study comparing 11 medication-free patients ( 7 women and 4 men, mean age \pm SD: $53.2 \pm$ 11.6 years) diagnosed with primary endogenous depression (DSM-III and 21-item Hamilton scale) with 11 normal subjects matched for sex, age and body weight, found significantly reduced mean basal serum $\mathrm{GH}$ levels and attenuated net $\mathrm{GH}$ response to GH-releasing hormone (GHRH) in depressed patients compared to controls, and this reduction was independent of sex, age or body weight. ${ }^{49}$ Analogous findings were reported in two other studies. ${ }^{50,51} \mathrm{It}$ is not surprising that adult men with GH-deficiency often have reduced BMD. ${ }^{52}$

\section{Inteleukin-6 (IL-6) and leptin}

The first report of high plasma levels of IL-6 and its soluble receptor (sIL-6R) in depressed men was from a study comparing 77 major depressed subjects (36 men and 25 women, mean age \pm SD: $33.8 \pm$ 1.5 years; diagnosed with DSM-III-R and the 24item Hamilton depression rating scale) with 38 healthy controls (21 men and 17 women, mean age \pm SD $36.6 \pm 1.3$ years $).{ }^{53}$ Analogous results were also reproduced by other groups. ${ }^{54,55}$

More recently, lower nocturnal levels of leptin, a hormone secreted by the white adipose tissue, were reported in 62 depressed subjects ( 27 men, 35 women) compared to 64 controls (32 men, 32 women). The difference remained significant after adjustment for the covariates of BMI, age, medication and smoking. ${ }^{56}$

Both IL-6 and leptin can influence bone metabolism. IL-6 and its receptor can modulate bone remodeling by regulating both osteoclast and osteoblast development and function. ${ }^{57}$ Leptin has been proposed to inhibit bone formation through a hypothalamic relay. ${ }^{58,59}$ 


\section{PROPOSED ENDOCRINE MODEL OF BONE LOSS IN DEPRESSION}

Prospective studies have associated depression and hip fractures. ${ }^{60}$ In many cases, osteoporosis in men can be attributed to another disease, ${ }^{2}$ however, in young adults, a major depressive episode was associated with lower BMD in men but not in women. ${ }^{61}$ Depression is involved in the pathogenesis of osteoporosis in a multifactorial and indirect fashion. ${ }^{62}$ We suggest that this mood disorder leads to hyperactivity of the HPA and sympatho-adrenal axes and suppression of the somatotrophic and gonadal axes, resulting in net bone loss (Figure 1).

The gender dimorphism in the epidemiology of both depression and osteoporosis is congruent with this hypothesis, with women patients showing a higher prevalence of both conditions than men. The fact that there are indications that the prevalence of osteoporosis in men may actually be higher than previously thought does not contradict this hypothesis, as there are ample indications that the prevalence of depression in men may also be higher than what has so far been considered.

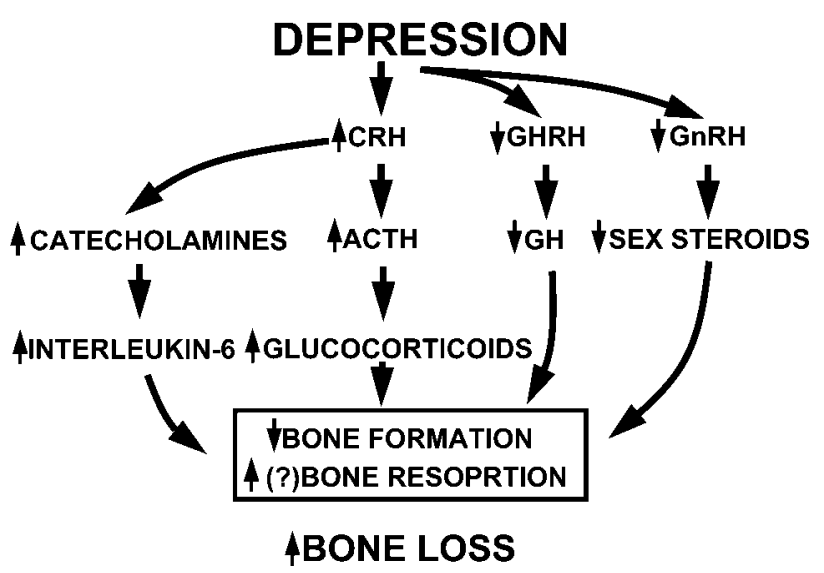

Figure 1. Depression leads to increased central CRH release, provoking higher ACTH and cortisol secretion, while lowered growth hormone (GHRH) and gonadotrophin-releasing (GnRH) hormone release from the hypothalamus suppress the secretion of GH and gonadal steroids, respectively. $\mathrm{CRH}$ also stimulates catecholamine release, inducing interleukin-6 production. The hyperactivity of hypothalamo-pituitary-adrenal and sympatho-adrenal axes, together with the suppression of somatotrophic and gonadal axes, result in primarily decreased bone formation, ultimately leading to net bone loss.

\section{REFERENCES}

1. Anonymous, 2000 Osteoporosis prevention, diagnosis, and therapy. NIH Consensus Statement 17: 1-45.

2. Licata A, 2003 Osteoporosis in men: suspect secondary disease first. Cleve Clin J Med 70: 247-254.

3. Looker AC, Orwoll ES, Johnston CC Jr, et al, 1997 Prevalence of low femoral bone density in older U.S. adults from NHANES III. J Bone Miner Res 12: 17611768.

4. Burgess E, Nanes MS, 2002 Osteoporosis in men: pathophysiology, evaluation and therapy. Curr Opin Rheumatol 14: 421-428.

5. Donaldson LJ, Cook A, Thomson RG, 1990 Incidence of fractures in a geographically defined population. $\mathbf{J}$ Epidemiol Community Health 44: 241-245.

6. Cooper C, Campion G, Melton LJ $3^{\text {rd }}, 1992$ Hip fractures in the elderly: a world-wide projection. Osteoporos Int 2: 285-289.

7. Melton LJ $3^{\text {rd }}$, Kan SH, Wahner HW, Riggs BL, 1988 Lifetime fracture risk: an approach to hip fracture risk assessment based on bone mineral density and age. J Clin Epidemiol 41: 985-994.

8. Center JR, Nguyen TV, Schneider D, Sambrook PN, Eisman JA, 1999 Mortality after all major types of osteoporotic fracture in men and women: an observational study. Lancet 353: 878-882.

9. Poor G, Atkinson EJ, O'Fallon WM, Melton LJ $3^{\text {rd }}$, 1995 Determinants of reduced survival following hip fractures in men. Clin Orthop Relat Res: 260-265.

10. Myers AH, Robinson EG, Van Natta ML, Michelson JD, Collins K, Baker SP, 1991 Hip fractures among the elderly: factors associated with in-hospital mortality. Am J Epidemiol 134: 1128-1137.

11. Ray NF, Chan JK, Thamer M, Melton LJ $3^{\text {rd }}, 1997$ Medical expenditures for the treatment of osteoporotic fractures in the United States in 1995: report from the National Osteoporosis Foundation. J Bone Miner Res 12: 24-35.

12. Task Force on DSM-IV 2000. In: Mood disorders (ed) Diagnostic and Statistical Manual of Mental Disorders DSM-IV-TR (Text Revision) Arlington, Va: American Psychiatric Association

13. Murray CJ, Lopez AD, 1996 Evidence-based health policy-lessons from the Global Burden of Disease Study. Science 274: 740-743.

14. Weissman MM, Bland RC, Canino GJ, et al, 1996 Cross-national epidemiology of major depression and bipolar disorder. JAMA 276: 293-299.

15. Kessler RC, McGonagle KA, Swartz M, Blazer DG, Nelson CB, 1993 Sex and depression in the National Comorbidity Survey. I: Lifetime prevalence, chronicity and recurrence. J Affect Disord 29: 85-96.

16. Nolen-Hoeksema S, 1987 Sex differences in unipolar depression: evidence and theory. Psychol Bull 101: 259282. 
17. Almeida OP, 1999 Sex playing with the mind. Effects of oestrogen and testosterone on mood and cognition. Arq Neuropsiquiatr 57: 701-706.

18. Merikangas KR, Weissman MM, Pauls DL, 1985 Genetic factors in the sex ratio of major depression. Psychol Med 15: 63-69.

19. Blehar MC, Oren DA, 1997 Gender Differences in Depression. Medscape Women's Health 2: 3.

20. Angst J, Dobler-Mikola A, 1984 Do the diagnostic criteria determine the sex ratio in depression? J Affect Disord 7: 189-198.

21. Moscicki EK, 1994 Gender differences in completed and attempted suicides. Ann Epidemiol 4: 152-158.

22. Walinder J, Rutzt W, 2001 Male depression and suicide. Int Clin Psychopharmacol 16: S21-S24.

23. Egeland JA, Hostetter AM, 1983 Amish Study, I: Affective disorders among the Amish, 1976-1980. Am J Psychiatry 140: 56-61

24. Loewenthal K, Goldblatt V, Gorton T, et al, 1995 Gender and depression in Anglo-Jewry. Psychol Med 25: 1051-1063.

25. Rutz W, 2001 Preventing suicide and premature death by education and treatment. J Affect Disord 62: 123129.

26. Robbins J, Hirsch C, Whitmer R, Cauley J, Harris T, 2001 The association of bone mineral density and depression in an older population. J Am Geriatr Soc 49: $732-736$.

27. Schweiger U, Deuschle M, Korner A, et al, 1994 Low lumbar bone mineral density in patients with major depression. Am J Psychiatry 151: 1691-1693.

28. Schweiger U, Weber B, Deuschle M, Heuser I, 2000 Lumbar bone mineral density in patients with major depression: evidence of increased bone loss at followup. Am J Psychiatry 157: 118-120.

29. Halbreich U, Rojansky N, Palter S, et al, 1995 Decreased bone mineral density in medicated psychiatric patients. Psychosom Med 57: 485-491.

30. Wong SYS, Lau EMC, Lynn H, et al, 2005 Depression and bone mineral density: is there a relationship in elderly Asian men? Results from Mr. Os (Hong Kong). Osteoporos Int 16: 610-615.

31. Iliffe S, Tai SS, Haines A, et al, 1993 Assessment of elderly people in general practice. 4 . Depression, functional ability and contact with services. Br J Gen Pract 43: 371-374.

32. Cizza G, Ravn P, Chrousos GP, Gold PW, 2001 Depression: a major, unrecognized risk factor for osteoporosis? Trends Endocrinol Metab 12: 198-203.

33. Gold PW, Loriaux DL, Roy A, et al, 1986 Responses to corticotropin-releasing hormone in the hypercortisolism of depression and Cushing's disease. Pathophysiologic and diagnostic implications. N Engl J Med 314: 1329-1335.

34. Linkowski P, Mendlewicz J, Leclercq R, et al, 1985 The 24-hour profile of adrenocorticotropin and corti- sol in major depressive illness. J Clin Endocrinol Metab 61: 429-438.

35. Deuschle M, Schweiger U, Weber B, et al, 1997 Diurnal activity and pulsatility of the hypothalamus-pituitary-adrenal system in male depressed patients and healthy controls. J Clin Endocrinol Metab 82: 234-238.

36. Carroll BJ, Curtis GC, Mendels J, 1976 Cerebrospinal fluid and plasma free cortisol concentrations in depression. Psychol Med 6: 235-244.

37. Roy A, Pickar D, De Jong J, Karoum F, Linnoila M, 1988 Norepinephrine and its metabolites in cerebrospinal fluid, plasma, and urine. Relationship to hypothalamic-pituitary-adrenal axis function in depression. Arch Gen Psychiatry 45: 849-857.

38. Gold PW, Wong ML, Goldstein DS, et al, 2005 Cardiac implications of increased arterial entry and reversible 24-h central and peripheral norepinephrine levels in melancholia.Proc Natl Acad Sci USA 102: 8303-8308.

39. Nemeroff CB, Widerlov E, Bissette G, et al, 1984 Elevated concentrations of CSF corticotropin-releasing factor-like immunoreactivity in depressed patients. Science 226: 1342-1344.

40. Roy A, Pickar D, Linnoila M, Chrousos GP, Gold PW, 1987 Cerebrospinal fluid corticotropin-releasing hormone in depression: relationship to noradrenergic function. Psychiatry Res 20: 229-237.

41. Ziegler R, Kasperk C, 1998 Glucocorticoid-induced osteoporosis: prevention and treatment. Steroids 63: 344-348.

42. Yesavage JA, Davidson J, Widrow L, Berger PA, 1985 Plasma testosterone levels, depression, sexuality, and age. Biol Psychiatry 20: 222-225.

43. Barrett-Connor E, Von Muhlen DG, Kritz-Silverstein D, 1999 Bioavailable testosterone and depressed mood in older men: the Rancho Bernardo Study. J Clin Endocrinol Metab 84: 573-577.

44. Schweiger U, Deuschle M, Weber B, et al, 1999 Testosterone, gonadotropin, and cortisol secretion in male patients with major depression. Psychosom Med 61: 292-296.

45. Finkelstein JS, Klibanski A, Neer RM, Greenspan SL, Rosenthal DI, Crowley WF Jr, 1987 Osteoporosis in men with idiopathic hypogonadotropic hypogonadism. Ann Intern Med 106: 354-361.

46. Diamond T, Stiel D, Posen S, 1989 Osteoporosis in hemochromatosis: iron excess, gonadal deficiency, or other factors? Ann Intern Med 110: 430-436.

47. Matzkin H, Chen J, Weisman Y, et al, 1992 Prolonged treatment with finasteride (a 5 alpha-reductase inhibitor) does not affect bone density and metabolism. Clin Endocrinol 37: 432-436.

48. Voderholzer U, Laakmann G, Wittmann R, et al, 1993 Profiles of spontaneous 24-hour and stimulated growth hormone secretion in male patients with endogenous depression. Psychiatry Res 47: 215-227.

49. Lesch KP, Laux G, Pfuller H, Erb A, Beckmann H, 
1987 Growth hormone (GH) response to GH-releasing hormone in depression. J Clin Endocrinol Metab 65: $1278-1281$.

50. Jarrett DB, Coble P, Kupfer DJ, Greenhouse JB, 1985 Sleep-related hormone secretion in depressed patients. Acta Psychiatr Belg 85: 603-614.

51. Steiger A, von Bardeleben U, Herth T, Holsboer F, 1989 Sleep EEG and nocturnal secretion of cortisol and growth hormone in male patients with endogenous depression before treatment and after recovery. J Affect Disord 16: 189-195.

52. Colao A, Di Somma C, Pivonello R, et al, 1999 Bone loss is correlated to the severity of growth hormone deficiency in adult patients with hypopituitarism. J Clin Endocrinol Metab 84: 1919-1924.

53. Maes M, Meltzer HY, Bosmans E, et al, 1995 Increased plasma concentrations of interleukin-6, soluble interleukin-6, soluble interleukin-2 and transferrin receptor in major depression. J Affect Disord 34: 301-309.

54. Sluzewska A, Rybakowski JK, Laciak M, Mackiewicz A, Sobieska M, Wiktorowicz K, 1995 Interleukin-6 serum levels in depressed patients before and after treatment with fluoxetine. Ann N Y Acad Sci 762: 474476.

55. Berk M, Wadee AA, Kuschke RH, O’Neill-Kerr A,
1997 Acute phase proteins in major depression. J Psychosom Res 43: 529-534.

56. Kraus T, Haack M, Schuld A, Hinze-Selch D, Pollmacher T, 2001 Low leptin levels but normal body mass indices in patients with depression or schizophrenia. Neuroendocrinology 73: 243-247.

57. Manolagas SC, 1998 The role of IL-6 type cytokines and their receptors in bone. Ann N Y Acad Sci 840: 194-204.

58. Ducy P, Amling M, Takeda S, et al, 2000 Leptin inhibits bone formation through a hypothalamic relay: a central control of bone mass. Cell 100: 197-207.

59. Takeda S, Elefteriou F, Levasseur R, et al, 2002 Leptin regulates bone formation via the sympathetic nervous system. Cell 111: 305-317.

60. Mussolino ME, 2005 Depression and hip fracture risk: the NHANES I epidemiologic follow-up study. Public Health Rep 120: 71-75.

61. Mussolino ME, Jonas BS, Looker AC, 2004 Depression and bone mineral density in young adults: results from NHANES III. Psychosom Med 66: 533-537.

62. Evans DL, Charney DS, Lewis L, et al, 2005 Mood disorders in the medically ill: scientific review and recommendations. Biol Psychiatry 58: 175-189. 